\title{
Additive value of transarterial embolization to systemic sirolimus treatment in kaposiform hemangioendothelioma
}

\author{
Richard Brill $^{1}$ | Wibke Uller ${ }^{2}$ | Veronika Huf ${ }^{2}$ | René Müller-Wille ${ }^{3}$ | \\ Irene Schmid $^{4}$ | Alexandra Pohl ${ }^{5}$ | Beate Häberle ${ }^{5}$ | Sybille Perkowski ${ }^{6}$ | \\ Katrin Funke $^{6}$ | Anne-Marie Till ${ }^{7}$ | Melchior Lauten ${ }^{7}$ | Jacob Neumann ${ }^{8}$ | \\ Christian Güttel $^{8}$ | Esther Heid ${ }^{9}$ | Franziska Ziermann ${ }^{9}$ | Axel Schmid ${ }^{10}$ | \\ Dieter Hüsemann $^{11}$ | Lutz Meyer ${ }^{12}$ | Peter B. Sporns ${ }^{13}$ | Regina Schinner ${ }^{14}$ \\ Vanessa F. Schmidt ${ }^{14}$ | Jens Ricke ${ }^{14}$ | Jochen Rössler ${ }^{15}$ | Friedrich G. Kapp ${ }^{16}$ | \\ Walter A. Wohlgemuth ${ }^{1}$ | Moritz Wildgruber ${ }^{14}$ (c) \\ ${ }^{1}$ Klinik und Poliklinik für Radiologie, Universitätsklinikum Halle, Halle/Saale, Germany \\ ${ }^{2}$ Institut für Röntgendiagnostik, Universitätsklinik Regensburg, Regensburg, Germany \\ ${ }^{3}$ Institut für diagnostische und interventionelle Radiologie, Universitätsmedizin Göttingen, Göttingen, Germany \\ ${ }^{4}$ Kinderklinik und Kinderpoliklinik im Dr. von Haunerschen Kinderspital, Klinikum der Universität München, Munich, Germany \\ ${ }^{5}$ Kinderchirurgische Klinik und Poliklinik im Dr. von Haunerschen Kinderspital, Klinikum der Universität München, Munich, Germany \\ ${ }^{6}$ Abteilung für Kinderchirurgie, Universitätsklinikum Münster, Münster, Germany \\ ${ }^{7}$ Klinik für Kinder- und Jugendmedizin, Pädiatrische Hämatologie und Onkologie, Universitätsklinikum Schleswig-Holstein, Lübeck, Germany \\ ${ }^{8}$ Klinik für Kinder- und Jugendmedizin, Helios Kliniken Schwerin, Schwerin, Germany \\ ${ }^{9}$ Klinik für Kinder und Jugendmedizin, Klinikum rechts der Isar, TU München, Munich, Germany \\ ${ }^{10}$ Radiologisches Institut Universitätsklinikum Erlangen, Erlangen, Germany \\ ${ }^{11}$ Klinik für Kinder- und Jugendmedizin, Werner Forßmann Krankenhaus, Eberswalde, Germany \\ ${ }^{12}$ Abteilung Kinderchirurgie-Zentrum für Vasculäre Malformationen Eberswalde (ZVM), Klinik für Kinder- und Jugendmedizin, Werner Forßmann Krankenhaus, \\ Eberswalde, Germany \\ ${ }^{13}$ Diagnostische und Interventionelle Neuroradiologie, Universitätsspital Basel, Basel, Switzerland \\ ${ }^{14}$ Klinik und Poliklinik für Radiologie, Klinikum der Universität München, Munich, Germany \\ ${ }^{15}$ Division of Pediatric Hematology/Oncology, Department of Pediatrics, Inselspital, Bern University Hospital, University of Bern, Bern, Switzerland \\ ${ }^{16}$ Division of Pediatric Hematology and Oncology, Department of Pediatrics and Adolescent Medicine, Medical Center - University of Freiburg, Faculty of Medicine, \\ University of Freiburg, Freiburg, Germany
}

Correspondence

Moritz Wildgruber, Klinik und Poliklinik für Radiologie, Klinikum der Universität München,

Marchioninistrasse 15, D-81377 Munich,

Germany.

Email: moritz.wildgruber@med.uni-

muenchen.de

\section{Abstract}

Kaposiform hemangioendothelioma (KHE) is a rare vascular tumor in children, which can be accompanied by life-threatening thrombocytopenia, referred to as KasabachMerritt phenomenon (KMP). The mTOR inhibitor sirolimus is emerging as targeted therapy in KHE. As the sirolimus effect on KHE occurs only after several weeks, we aimed

Abbreviations: ACA, acetylsalicylate acid; CR, complete response; DIC, disseminated intravascular coagulation; KHE, kaposiform hemangioendothelioma; KMP, Kasabach-Merritt phenomenon; MRI, magnetic resonance imaging; mTOR, mammalian target of rapamycin; PD, progressive disease; PR, partial response; SD, stable disease; WHO, World Health Organization.

Walter A. Wohlgemuth and Moritz Wildgruber contributed equally to this work.

This is an open access article under the terms of the Creative Commons Attribution License, which permits use, distribution and reproduction in any medium, provided the original work is properly cited.

(C) 2020 The Authors. International Journal of Cancer published by John Wiley \& Sons Ltd on behalf of UICC. 
to evaluate whether additional transarterial embolization is of benefit for children with KHE and KMP. Seventeen patients with KHE and KMP acquired from 11 hospitals in Germany were retrospectively divided into two cohorts. Children being treated with adjunct transarterial embolization and systemic sirolimus, and those being treated with sirolimus without additional embolization. Bleeding grade as defined by WHO was determined for all patients. Response of the primary tumor at 6 and 12 months assessed by magnetic resonance imaging (MRI), time to response of KMP defined as thrombocyte increase $>150 \times 10^{3} / \mu \mathrm{L}$, as well as rebound rates of both after cessation of sirolimus were compared. $\mathrm{N}=8$ patients had undergone additive embolization to systemic sirolimus therapy, sirolimus in this group was started after a mean of $6.5 \pm 3$ days following embolization. $\mathrm{N}=9$ patients were identified who had received sirolimus without additional embolization. Adjunct embolization induced a more rapid resolution of KMP within a median of 7 days vs 3 months; however, tumor response as well as rebound rates were similar between both groups. Additive embolization may be of value for a more rapid rescue of consumptive coagulopathy in children with $\mathrm{KHE}$ and KMP compared to systemic sirolimus only.

\section{KEYWORDS}

coagulopathy, embolization, Kaposiform hemangioendothelioma, Kasabach-Merritt phenomenon

\section{1 | INTRODUCTION}

Kaposiform hemangioendothelioma (KHE) is a rare vascular tumor affecting children with an incidence $<0.1: 100.000 .^{1,2} \mathrm{KHE}$ frequently manifests as a rapidly growing mass of the skin and musculoskeletal system, infiltrating adjacent tissues. In up to $70 \% \mathrm{KHE}$ is complicated by a lifethreatening consumptive coagulopathy with severe thrombocytopenia: Kasabach-Merritt phenomenon (KMP). ${ }^{1,3}$ Different from disseminated intravascular coagulation (DIC), intratumoral platelet trapping through activated endothelium carrying a partial lymphatic phenotype results in severe thrombocytopenia. ${ }^{4}$ This intratumoral coagulopathy accounts for a high mortality in $\mathrm{KHE}$ of $10 \%$ to $30 \%$ in KHE patients. ${ }^{5}$ As curative surgical resection of $\mathrm{KHE}$ is frequently not possible and is additionally associated with a high mortality, ${ }^{6}$ various systemic treatment options have been suggested including corticosteroids, vincristine, ${ }^{7}$ interferon-alpha and platelet inhibition. ${ }^{8,9}$ In 2013, a consensus document recommended intravenous vincristine and either oral prednisolone or intravenous methylprednisolone as first-line treatment of $\mathrm{KHE}$ associated with $\mathrm{KMP}{ }^{10}$ while two more recent meta-analyses have identified vincristine as safer and more effective compared to corticosteroids. ${ }^{7}$ Image-guided embolization has been shown to induce a rapid decrease of the tumor mass, but the effect is considered to be only temporary. ${ }^{10,11}$ Besides the aforementioned approaches, the mammalian target of rapamycin (mTOR) inhibitor sirolimus, a substrate for CYP3A4, targeting the PI3K-AktmTOR pathway is emerging as novel treatment option in KHE. ${ }^{12,13}$ While traditionally used to inhibit the activation of T-lymphocytes in transplant rejection, multiple reports have recently shown the efficiency of sirolimus in treating both $\mathrm{KHE}$ and the associated $\mathrm{KMP}^{14}{ }^{14}$ In addition, sirolimus

\section{What's new?}

Kaposiform hemangioendothelioma (KHE) is a rare vascular tumor in children. Up to $70 \%$ of these patients also develop a life-threatening, consumptive coagulopathy known as Kasabach-Merritt Phenomenon (KMP). Sirolimus is proving to be an effective therapy for both KHE and KMP. However, it can take several weeks for sirolimus to have an effect. In this study, the authors found that initial treatment with embolization provides a rapid rescue from the symptoms of KMP. Image-guided, transarterial embolization may thus provide a valuable adjunct to sirolimus therapy of KHE/HMP.

seems equally effective for initial therapy ${ }^{15}$ and for steroid-resistant $\mathrm{KHE}^{16}$ showing low rates of recurrence, ${ }^{17}$ although relapse after cessation of sirolimus treatment has been observed. ${ }^{18}$ Sirolimus treatment on the one hand initiates shrinkage and remission of the tumor and similarly it addresses KMP over time, leading to a normalization of thrombocyte counts within a period of approximately 20 days. ${ }^{15-17,19}$

Therapy of complicated KHE thus aims at (a) remission of the primary tumor, (b) rapid resolution of the life-threatening consumptive coagulopathy and (c) prevention of recurrence of either one. As sirolimus is emerging as the most effective systemic approach to KHE with good results in tumor remission, and as embolization has the potential to rapidly resolve the severe intratumoral consumptive coagulopathy by excluding the abnormal endothelium from the 
systemic circulation, we evaluated the added value of transarterial embolization to systemic sirolimus in children with KHE/KMP in a retrospective multicenter cohort.

\section{2 | PATIENTS AND METHODS}

\section{1 | Study design}

The study was performed as a retrospective analysis. Seventeen patients with Kaposiform hemangioendothelioma were recruited from 11 German tertiary care hospitals from March 2012 to November 2019. Patients were divided into two groups: patients undergoing embolization as additive treatment to systemic sirolimus and patients receiving sirolimus without additional embolization.

\subsection{Patients and disease manifestation}

Demographic, clinical, laboratory and procedural data were retrieved from electronic patient records. Two of the patients reported have been previously published, including additional information about the cases. ${ }^{20,21}$ Clinical evaluation included assessment of tenderness of the lesion, expansive character of the mass, skin temperature and discoloration, pulsations/AV-shunting, hemorrhage and associated lymphedema.

Bleeding grade associated with $\mathrm{KHE}$ was classified according to the World Health Organization (WHO) scheme. ${ }^{22}$

\subsection{Treatment and response assessment}

In patients receiving additive embolization, the procedure was carried out under general anesthesia via a $4 \mathrm{~F}$ groin access. Transarterial embolization was performed either using particles or ethylene vinyl alcohol copolymer. The procedure was considered technically successful if $\geq 80 \%$ of the tumor vasculature was occluded at the end of the intervention. Patients undergoing embolization underwent additional treatment with weight-adapted acetylsalicylate acid, weight-adapted, from 2 to $20 \mathrm{mg} /$ day for 6 months. Systemic sirolimus was given at a dose of 0.1 to $1.8 \mathrm{mg} / \mathrm{kg} / \mathrm{m}^{2}$ to achieve serum levels of 4 to $15 \mathrm{ng} / \mathrm{L}$.

Disease extent and therapy response were assessed on magnetic resonance images (MRI). Response to therapy was specifically assessed at 6 and 12 months after initiation of therapy, clinically as well as by MRI. Similarly, blood tests were performed at respective time points. Response to therapy was defined in two categories (a) normalization of coagulopathy, defined as platelet increase $>150 \times 10^{3} / \mu \mathrm{L}$ and (b) response of KHE itself (graded as complete response $C R$, partial response $P R$, stable disease $S D$ and progressive disease PD) according the Response Evaluation Criteria in Solid Tumors. As KHE leaves residual scar tissue both at the skin and within connective tissue, $\mathrm{CR}$ was defined as the absence of viable tumor on contrast-enhanced MRI, without taking nonenhancing residual scar tissue into account. Rebound of KHE and KMP after sirolimus discontinuation was defined as a switch to progressive disease either from SD, PR or CR after cessation of sirolimus treatment, defined either by an increase in tumor size or a decrease of platelet counts $<150 \times 10^{3} / \mu \mathrm{L}$.

\subsection{Data analysis and statistics}

Data are shown as mean $\pm \mathrm{SE}$, median or as relative percentages. Group comparisons were performed between patients undergoing sirolimus with additive embolization of $\mathrm{KHE}$ and patients receiving sirolimus without additional image-guided embolization. Comparison of demographic patient data was performed using Fisher's exact test for qualitative data or, depending on normality of data, either two-sample $t$-test or Mann-Whitney $U$ test for quantitative data. Response to therapy was compared similarly with Fisher's exact test and Mann-Whitney $U$ test. For comparison of response of KMP, median time of thrombocyte count normalization was compared between the two groups using Kaplan-Maier analysis and log-rank test. A $P$ value $<.05$ was considered significant. Analysis was performed using the GraphPad Prism version 7 (GraphPad Software, San Diego, CA) as well as SAS Version 9.4 for Windows (SAS Institute Inc, Cary, NC).

\section{$3 \mid$ RESULTS}

\section{1 | Patient demographics}

In total, 17 children with KHE and accompanying KMP were identified and included (11 male, 6 female) with no significant difference of sex distribution between the groups $(P=.131)$. Patients in the embolization group ( $n=8$ ) were younger (11.3 \pm 7 months vs $41.8 \pm 19$ months), however with no statistical difference $(P=.219)$. Histology was obtained in 15 of 17 (88\%) of cases. In the remaining two patients, the diagnosis was evident from the clinical picture and laboratory findings, thus histological assessment was omitted. A short case description of each patient is presented in Supplementary Table 1.

Bleeding grades were classified according to the World Health Organization (WHO) scale: no bleeding was reported in 1 patient, Grade 1 in 2 patients, Grade 2 in 4 patients, Grade 3 in 10 patients and Grade 4 in none of the patients. There was no significant difference between bleeding scores at baseline in patients with embolization (25\% Grade 1, 12.5\% Grade 2 and 62.5\% Grade 3) and patients without embolization (11.1\% Grade 1, 33.3\% Grade 2, and 55.6\% Grade 3; $P=.908$ ). Median thrombocyte count at baseline was $38.5 \times 10^{3} / \mu \mathrm{L}$ in group of patients with adjunct embolization vs $36.0 \times 10^{3} / \mu \mathrm{L}$ in the group without additional embolization $(P=.408)$. Median fibrinogen levels at baseline were $132 \mathrm{mg} / \mathrm{dL}$ in group of patients with adjunct embolization vs $122.5 \mathrm{mg} / \mathrm{dL}$ in the group without additional embolization $(P=.798)$. Median $\mathrm{D}$-dimer levels at baseline were $16.95 \mathrm{mg} / \mathrm{L}$ in group of patients with adjunct embolization vs $18.15 \mathrm{mg} / \mathrm{L}$ in the group without additional embolization $(P=.825)$. 
TAB LE 1 Tumor response of kaposiform hemangioendothelioma

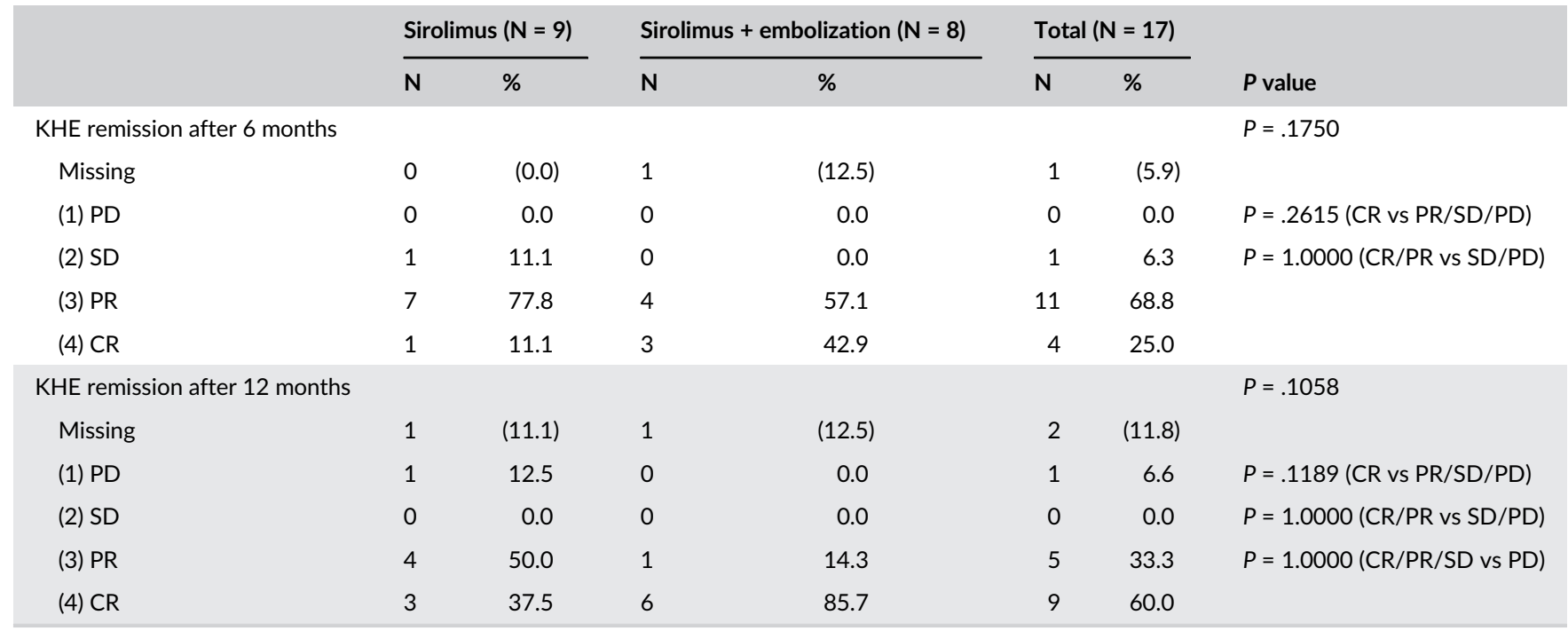

Note: Tumor response of KHE to systemic sirolimus \pm embolization was compared with respect to progressive disease (PD), stable disease (SD), partial response (PR) and complete response (CR), without revealing statistically significant differences between the two cohorts.
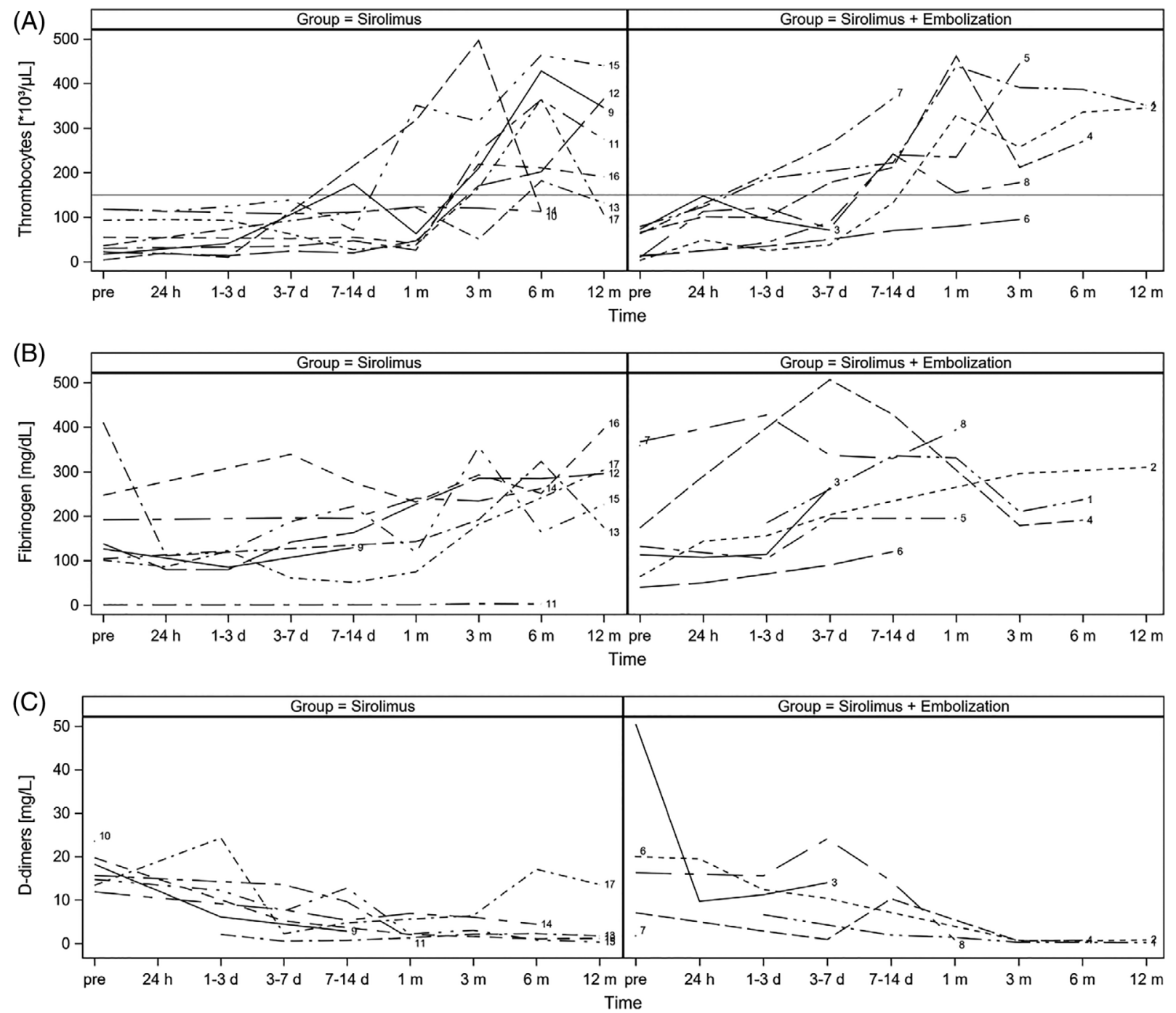

FIGURE 1 Response of Kasabach-Merrit phenomenon. Laboratory course of thrombocyte counts (A), fibrinogen (B), and D-dimers (C) is shown for children receiving adjunct embolization to systemic sirolimus ( $n=8$, right panels) compared with patients receiving sirolimus without additive embolization ( $n=9$, left panels) 


\section{2 | Treatment and response}

Embolization was performed in $n=8 / 17$ (47\%) of the patients; sirolimus without additional embolization was used in $n=9 / 17$ (53\%) patients. Embolization with devascularization of $>80 \%$ of tumor vasculature was technically successful in $100 \%$, without major periprocedural complications, especially no arterial thrombosis or dissection occurred. In 2 of 8 patients, two subsequent embolization procedures were performed, while in 6 of 8 patients one treatment cycle was sufficient to complete the procedure. Sirolimus was applied with a mean dose of $0.46 \pm 0.1 \mathrm{mg} / \mathrm{kg} / \mathrm{m}^{2}$ and was given for 278 \pm 56 days in the embolization group, and with a mean dose of 0.58 $\pm 0.2 \mathrm{mg} / \mathrm{kg} / \mathrm{m}^{2}$ given for $434 \pm 69$ days in the group without embolization ( $P=.677$ for dose, $P=.107$ for time period differences). In the embolization group, sirolimus was started $6.5 \pm 3$ days following the embolization procedure.

Tumor response to therapy revealed no statistically significant differences between the two groups (Table 1), PR or CR was achieved in a majority of patients (Supplementary Figure 1).

One patient had previously been treated by embolization only as systemic therapy was initially refused by the parents. Embolization in this case initially led to a rapid regression of $\mathrm{KHE}$ and immediate release from KMP, however, with complete relapse of $\mathrm{KHE}$ together with KMP after 3 months (Supplementary Figure 2).

Response of KMP differed between the two treatment regimens with respect to thrombocyte counts, while fibrinogen and D-dimers did not reveal marked differences (Figure $1 \mathrm{~A}-\mathrm{C}$ ). Patients with additive embolization were faster to achieve a thrombocyte count of $150 \times 10^{3} / \mu \mathrm{L}$ than patients without embolization $(\mathrm{HR}=0.39$, $P$-value log-rank $=.061$, Figure 2 ). The median time to normalization occurred within the 7 to 14 days interval in patients treated with embolization plus sirolimus and at the 3 months in patients treated with sirolimus only. At 6 and 12 months, KMP had resolved in patients with and without additive embolization. No major bleeding event was reported for any patients in both groups after initiation of therapy.
Rebound of KHE together with KMP after discontinuation of sirolimus occurred in 0 of 8 patients in the embolization group and in 3 of 9 patients in the group without embolization $(P=.200)$.

Overall, 2 of 8 patients in the embolization group died within 12 months: one child at 11.5 months after embolization and sirolimus treatment, with initially good response, due to metastatic disease confirmed by autopsy (Patient 8 ). The child's death was attributed to congestive heart failure at the age of 8 days, 6 days after embolization and sirolimus initiation, before full effects of systemic therapy could become effective. This death was attributed at least partially to the high arteriovenous shunting of the KHE together with a patent ductus arteriosus (Patient 3). In the latter case, emergency embolization was performed as a rescue procedure; however, the child passed away on the day after embolization. Mean follow-up was $667 \pm 151$ days in patients with embolization and $1501 \pm 361$ days in patients without additional embolization $(P=.060)$.

\section{4 | DISCUSSION}

Kaposiform hemangioendothelioma is a rare vascular tumor in infants associated with potentially life-threatening severe thrombocytopenia. ${ }^{1-3}$ In KMP, pathologically activated intratumoral endothelium causes local platelet and fibrinogen sequestration leading to severe thrombocytopenia, with or without lowered fibrinogen and altered

D-dimers levels. ${ }^{4,23}$ In 2013, a consensus document recommended intravenous vincristine together with oral prednisolone as the treatment of choice in $\mathrm{KHE}$ presenting with $\mathrm{KMP},{ }^{10}$ with the positive effect of vincristine confirmed in a large meta-analysis. ${ }^{7}$ In recent years, sirolimus has emerged as a potent agent in KHE. Retrospective multicenter studies recommend sirolimus as a potential first-line treatment alone or as part of a multimodal approach. ${ }^{14}$ Sirolimus has been shown to provide recovery from life-threatening KMP after a period of 3 weeks of oral application. ${ }^{15-17,19}$ With respect to this period of severe coagulopathy, our aim was to evaluate whether
FIGURE 2 Kaplan-Meier analysis of thrombocyte course after initiation of therapy. To compare response of consumptive coagulopathy time periods where compared between start of therapy until patients exceeded a thrombocyte count $>150 \times 10^{3} / \mu \mathrm{L}$. Hazard ratio of children receiving sirolimus without additive embolization was 0.39 compared with children undergoing additive embolization ( $P$ value log-rank .061)

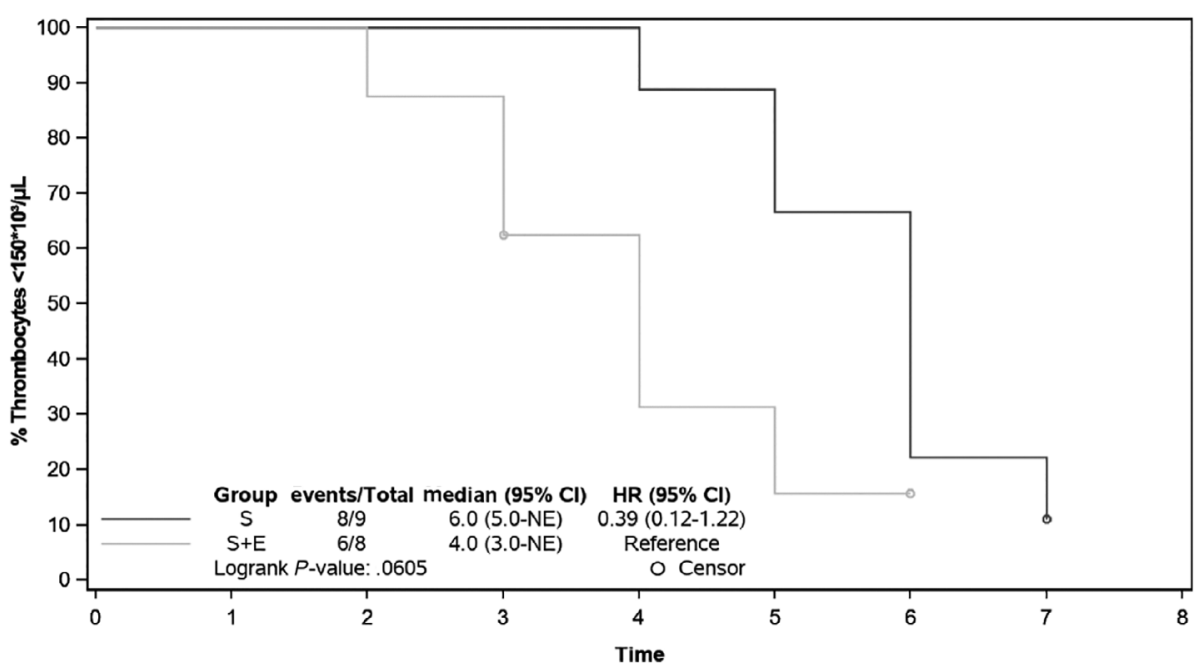


transarterial embolization in adjunct to sirolimus treatment provides a more rapid resolution of KMP and has a potential effect on tumor outcome.

Our results suggest that KMP resolution occurs more rapidly after embolization plus sirolimus; however, tumor response was similar between both treatment regimens. Interestingly in the cohort of children receiving sirolimus without embolization, 3 of 9 patients suffered rebound of KHE/KMP within a 1-year period, whereas in the combined treatment group no rebound was observed.

Transarterial embolization has been used in the past to treat $\mathrm{KHE}$ and KMP, although most reports similarly use embolization only in combination with systemic chemotherapy, mostly vincristine. ${ }^{11,24}$ Embolization alone seems to be associated with a high relapse rate of KHE. Of note, one patient in our cohort had initially been treated by embolization alone leading initially to a rapid regression of $\mathrm{KHE}$ and immediate release from KMP; however, complete relapse of $\mathrm{KHE}$ together with KMP occurred after 3 months. In our cohort, embolization was technically successful in all patients and with exception of two patients, only a single treatment cycle was required to rapidly rescue children from KMP. Embolization may therefore bridge the gap between occurrence of life-threatening KMP and the effect of systemic treatment. In our study, embolization was regularly combined with platelet function inhibition by ASA, which may exert two different effects in this scenario. On the one hand, platelet inhibition may reduce intralesional platelet sequestration. On the other hand, children with consumptive coagulopathy appear to have a hyperplastic bone marrow, as evidenced by the rapid endogenous increase of thrombocytes within a few days after embolization. Thrombocytopenia may thereby potentially switch into thrombophilia following embolization and ASA can potentially counteract this effect. Several reports have demonstrated beneficial effects of platelet function inhibition in KHE in combination therapies. ${ }^{8,9}$

Initially, vincristine was considered the chemotherapeutic agent of choice for KHE, yet the beneficial effects of sirolimus are becoming increasingly evident. Although chemotherapeutic agents such as vincristine exert unspecific effects on $\mathrm{KHE}$, somatic or mosaic mutations of the PI3KCA gene provide a clear molecular rationale for sirolimus treatment in KHE. Sirolimus seems to exert both antiproliferative and antiangiogenic/-lymphangiogenic effects by inhibiting mTOR, a serine-threonine kinase regulated by $\mathrm{PI} 3 \mathrm{~K}$. Recent studies reported long-term follow-up after KHE treatment with sirolimus. Wang et al report a follow-up period of 28 months with only mild side effects and no report of recurrence. ${ }^{17}$ Although previously dosing was calculated to achieve target sirolimus levels of 10 to $15 \mathrm{ng} / \mathrm{L}$, our cohort applied significantly lower sirolimus dosing. Similarly, other reports suggest that levels around $5 \mathrm{ng} / \mathrm{L}$ may be sufficient for successful treatment of $\mathrm{KHE}^{25}$ Decreased dose regimens may explain the low rate of systemic side effects of sirolimus reported in the vascular anomalies literature compared to its use in transplantation medicine.

Our study is limited by the small cohort size and the retrospective study design. Moreover, the patient cohort reported is heterogeneous with regard to age and more importantly with respect to previous and concomitant systemic treatments, which may all have impact on the long-term outcome and recurrence rates. ASA treatment routinely performed in the embolization group and not given in the nonembolization cohort may cause additional bias; however, its influence on tumor response is considered negligible. Overall, our study is limited in evidence but can serve as a hypothesis generating work. Further studies are therefore requested to answer these questions with more robust evidence. Of note, none of the patients without embolization experienced severe bleeding complications in the period prior to platelet count normalization. Thus, the clinical benefit of additional embolization is yet unknown and has to be weighed against the potential risk of intraarterial embolization in small children. At this point, embolization cannot be recommended routinely for KHE/KMP treatment; however, if embolization is being performed for KMP, children should be placed on systemic therapy right after to achieve a sustained response.

In summary, our study suggests that transarterial embolization may add to systemic sirolimus in the treatment of kaposiform hemangioendothelioma and provides are more rapid resolution of potentially life-threatening Kasabach-Merritt phenomenon. However, in this small cohort no significant differences in resolution of $\mathrm{KHE}$ itself were observed.

\section{ACKNOWLEDGMENT}

Open access funding enabled and organized by Projekt DEAL.

\section{CONFLICT OF INTEREST}

The authors declare no conflict of interest.

\section{DATA AVAILABILITY STATEMENT}

Original data are available upon request.

\section{ETHICS STATEMENT}

The study was approved by the institutional review board (Protocol No. 2019-667-f-S). Informed consent for study participation was waived due to the retrospective character of the study. Informed consent for publication of patient's images has been obtained from the parents.

\section{ORCID}

Moritz Wildgruber (D) https://orcid.org/0000-0002-7228-6963

\section{REFERENCES}

1. Croteau SE, Liang MG, Kozakewich HP, et al. Kaposiform hemangioendothelioma: atypical features and risks of KasabachMerritt phenomenon in 107 referrals. J Pediatr. 2013;162: 142-147.

2. Wildgruber M, Sadick M, Müller-Wille R, Wohlgemuth WA. Vascular tumors in infants and adolescents. Insights Imaging. 2019;10:30.

3. Ji Y, Yang K, Peng S, et al. Kaposiform haemangioendothelioma: clinical features, complications and risk factors for Kasabach-Merritt phenomenon. Br J Dermatol. 2018;179:457-463.

4. O'Rafferty C, O'Regan GM, Irvine AD, Smith OP. Recent advances in the pathobiology and management of Kasabach-Merritt phenomenon. Br J Haematol. 2015;171:38-51. 
5. Sarkar M, Mulliken JB, Kozakewich HP, Robertson RL, Burrows PE. Thrombocytopenic coagulopathy (Kasabach-Merritt phenomenon) is associated with Kaposiform hemangioendothelioma and not with common infantile hemangioma. Plast Reconstr Surg. 1997;100: 1377-1386.

6. Drolet BA, Scott LA, Esterly NB, Gosain AK. Early surgical intervention in a patient with Kasabach-Merritt phenomenon. J Pediatr. 2001; 138:756-758.

7. Liu XH, Li JY, Qu XH, et al. Treatment of kaposiform hemangioendothelioma and tufted angioma. Int J Cancer. 2016;139:1658-1666.

8. Fernandez-Pineda I, Lopez-Gutierrez JC, Chocarro G, BernabeuWittel J, Ramirez-Villar GL. Long-term outcome of vincristine-aspirinticlopidine (VAT) therapy for vascular tumors associated with Kasabach-Merritt phenomenon. Pediatr Blood Cancer. 2013;60: 1478-1481.

9. MacFarland SP, Sullivan LM, States LJ, et al. Management of refractory pediatric Kaposiform hemangioendothelioma with sirolimus and aspirin. J Pediatr Hematol Oncol. 2018;40:e239-e242.

10. Drolet BA, Trenor CC 3rd, Brandão LR, et al. Consensus-derived practice standards plan for complicated Kaposiform hemangioendothelioma. J Pediatr. 2013;163:285-291.

11. Yesudian PD, Parslew R, Klafowski J, Gould D, Pizer B. Tufted angioma-associated Kasabach-Merritt syndrome treated with embolization and vincristine. Plast Reconstr Surg. 2008;121:692-693.

12. Freixo C, Ferreira V, Martins J, et al. Efficacy and safety of sirolimus in the treatment of vascular anomalies: a systematic review. J Vasc Surg. 2020;71:318-327.

13. Sakata N, Suenobu SI, Okano M, Ueda S, Kimura M, Takemura T. Impact of sirolimus treatment for refractory kaposiform hemangioendothelioma with exacerbation of the disease 10 years after initial diagnosis. Rare Tumor. 2018;10:2036361318776185.

14. Ji Y, Chen S, Xiang B, et al. Sirolimus for the treatment of progressive kaposiform hemangioendothelioma: a multicenter retrospective study. Int J Cancer. 2017;141:848-855.

15. Wang H, Guo X, Duan Y, Zheng B, Gao Y. Sirolimus as initial therapy for kaposiform hemangioendothelioma and tufted angioma. Pediatr Dermatol. 2018;35:635-638.

16. Tan X, Zhang J, Zhou S, Liu Z, Zhang T, Xia J. Successful management of steroid-resistant vascular tumors associated with the Kasabach-Merritt phenomenon using sirolimus. J Dermatol. 2018;45: 580-583.

17. Wang Z, Yao W, Sun H, et al. Sirolimus therapy for kaposiform hemangioendothelioma with long-term follow-up. J Dermatol. 2019; 46:956-961.
18. Boccara O, Puzenat E, Proust S, et al. The effects of sirolimus on Kasabach-Merritt phenomenon coagulopathy. Br J Dermatol. 2018; 178:e114-e116.

19. Nadal M, Giraudeau B, Tavernier E, Jonville-Bera AP, Lorette G, Maruani A. Efficacy and safety of mammalian target of rapamycin inhibitors in vascular anomalies: a systematic review. Acta Derm Venereol. 2016;96:448-452.

20. Schmid I, Klenk AK, Sparber-Sauer M, Koscielniak E, Maxwell R, Häberle B. Kaposiform hemangioendothelioma in children: a benign vascular tumor with multiple treatment options. World J Pediatr. 2018;14:322-329.

21. Schroeder U, Lauten M, Stichtenoth G, Gebhard MP, Buchholz M, Kaiser MM. Laryngomalacia and complicated, life-threatening mTORpositive Kaposiform hemangioendothelioma cured by supraglottoplasty and sirolimus. Klinische Padiatrie. 2014;226:362-368.

22. Josephson CD, Granger S, Assmann SF, et al. Bleeding risks are higher in children versus adults given prophylactic platelet transfusions for treatment-induced hypoproliferative thrombocytopenia. Blood. 2012; 120:748-760.

23. Adams DM, Brandão LR, Peterman CM, et al. Vascular anomaly cases for the pediatric hematologist oncologists-an interdisciplinary review. Pediatr Blood Cancer. 2018;65.

24. Tan X, Chen M, Zhang J, et al. Treatment of corticosteroidresistant vascular tumors associated with the Kasabach-Merritt phenomenon in infants: an approach with transcatheter arterial embolization plus vincristine therapy. J Vasc Interv Radiol. 2016; 27:569-575

25. Mariani LG, Schmitt IR, Garcia CD, Kiszewski AE. Low dose sirolimus treatment for refractory tufted angioma and congenital kaposiform hemangioendothelioma, both with Kasabach-Merritt phenomenon. Pediatr Blood Cancer. 2019;66:e27810.

\section{SUPPORTING INFORMATION}

Additional supporting information may be found online in the Supporting Information section at the end of this article.

How to cite this article: Brill R, Uller W, Huf V, et al. Additive value of transarterial embolization to systemic sirolimus treatment in kaposiform hemangioendothelioma. Int. J. Cancer. 2020;1-7. https://doi.org/10.1002/ijc.33406 